\title{
RUNNING PERFORMANCE AND PHYSIOLOGICAL CHARACTERISTICS OF ONE MAN OVER A TWENTY-YEAR PERIOD
}

\author{
P. BALE, Chelsea School of Human Movement, Brighton Polytechnic
}

\section{INTRODUCTION}

In general there is a slow decline in physical performance during maturity which becomes more rapid with increasing age. Maximum oxygen uptake $\left(\mathrm{VO}_{2}\right.$ max $)$ is regarded as one of the best measurements of physical working capacity; and cross-sectional studies suggest that men lose about 11-14 ml. $\mathrm{kg}^{-1} \mathrm{~min}^{-1}$ of aerobic power between the ages of 25 and 55 years (Åstrand and Rodahl, 1977; Quirion et al, 1987; Shephard, 1978). Longitudinal studies report quite

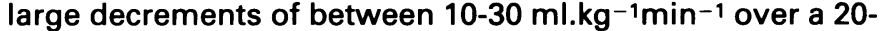
year period between ages 30 and 50 years (Åstrand et al, 1973; Dehn and Bruce, 1972; Robinson et al, 1975), depending on whether the subjects were inactive, or were active sportsmen. Many researchers suggest that this loss in physiological performance is more related to decreased habitual activity than to age itself. Thus, although it is accepted that the functional capacity of the cardiorespiratory system does decrease with age, this decrease can be minimised by regular physical activity (Barnard et al, 1979). De Vries (1980) further comments that the relative capacity for improvement in performance is probably not greatly different in middle age from that in youth. Thus the purpose of the present study was to examine the effect of training on performance of a subject between the ages of 30 and 50 years.

\section{METHOD}

A male subject, initially aged 30 years, ran a series of twelve training runs, during eight weeks between the middle of October and December every year for twenty years. The training run involved running a distance of approximately three miles over roads, a gravel path, up steps and a steep slope. The run was a maximal effort on each occasion.

Each run was timed to the nearest second and, in addition, every four years the subject was measured anthropometrically and physiologically. Height and weight were measured using a Stadiometer and Avery $120 \mathrm{~kg}$ scales, and the Heath-Carter method was used to assess the subject's somatotype (Heath and Carter, 1967). A progressive cycle ergometer test to exhaustion was used to determine maximum heart rate and $\mathrm{VO}_{2}$ max. Cardiac frequency was monitored throughout each ergometer test, using bipolar chest electrodes in conjunction with an ECG amplifier and pen rocorder (Devises).

On the first three test occasions expired air analysis was performed using Standard Douglas bag techniques. On the last three test occasions the expired air was passed directly through a Parkinson-Cowan dry gas meter, and oxygen analysis was made using a Servomex oxygen analyser, calibrated prior to and following each test, using gases of known concentration. Oxygen uptake values were expressed at STPD. As carbon dioxide was not analysed, oxygen uptake was calculated on the assumption that

Address for correspondence:

Dr. P. Bale

Chelsea School of Human Movement

Brighton Polytechnic

Trevin Towers

Denton Road

Eastbourne BN20 7SP inspiratory and expiratory volumes were equal. Consequently a small and unknown variation in the calculation of the $\mathrm{VO}_{2}$ values may have occurred. Given the above constraints, the measurements taken every four years over the 20-year training period were standardised as closely as possible.

During the first ten years, in addition to the training runs in October and December, the subject played club rugby and continued to run twice a week during the rugby season. After he stopped playing rugby at $\mathbf{4 0}$ years of age his main exercise, other than the training runs, was to walk to work, a distance of approximately 15-20 miles (25-35 km) per week.

\section{RESULTS AND DISCUSSION}

The anthropometric and physiological measures made every four years are represented in Table I. In order to discuss performance in relation to these anthropometric and physiological parameters, the mean scores of the training runs over a four-year period were calculated and are presented graphically (Fig. 1).

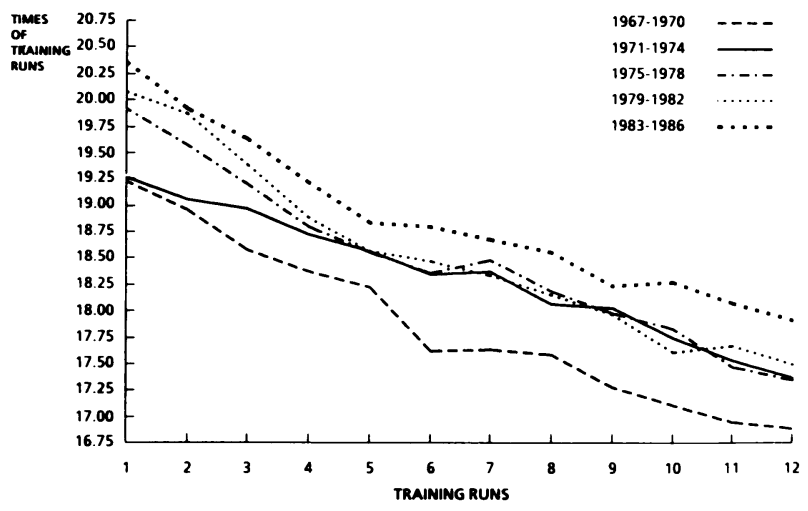

Fig. 1: Mean scores of the Training Runs over each four year period between 1967 and 1986.

The subject's weight increased by only $2.3 \%$ over the 20 year period, which is much less than the average weight increase of about $8 \%$ for males between 30 and 50 years. There was also a very slight decrease in height. The mesomorphy rating remained the same but there was an increase in endomorphy of one and a corresponding decrease in ectomorphy of half a rating. With the slight increase in weight, these changes suggest that there may have been a small increase in the fat content of the body. However, as somatotype is a morphological frame of reference, and body composition was not measured, this conclusion is only tentative.

There was a decrease in $\mathrm{VO}_{2}$ max from 3.62 to 3.2 litres per minute, and $\mathrm{VO}_{2}$ max in relation to weight from 54.0 to $46.4 \mathrm{ml} . \mathrm{kg}^{-1} \mathrm{~min}^{-1}$, representing a decrease of $11.8 \%$ and $13.7 \%$ respectively. Over the 20 years, therefore, there was a decrease of $7.4 \mathrm{ml} . \mathrm{kg}^{-1} \mathrm{~min}^{-1}$ or $0.37 \mathrm{ml} . \mathrm{kg}^{-1} \mathrm{~min}^{-1}$ per year. These findings are similar to those of Dehn and Bruce (1972) in their longitudinal study of active males, to the active runners in Costill and Winrow's study (1970) and the masters runners in Barnard, Grimditch and Wilmore's study 
TABLE I

Anthropometric and physiological variables

\begin{tabular}{|c|c|c|c|c|c|c|c|c|c|}
\hline \multirow[b]{2}{*}{ Date } & \multirow{2}{*}{$\begin{array}{c}\text { Age } \\
\mathrm{yr}\end{array}$} & \multirow{2}{*}{$\begin{array}{l}\text { Weight } \\
\text { kg }\end{array}$} & \multirow{2}{*}{$\begin{array}{l}\text { Height } \\
\text { cm }\end{array}$} & \multicolumn{3}{|c|}{ Somatotype } & \multirow{2}{*}{$\begin{array}{c}\text { Max } \\
\text { heart rate } \\
\text { beat. } \min ^{-1}\end{array}$} & \multicolumn{2}{|c|}{$\begin{array}{c}\text { Maximum oxygen } \\
\text { uptake }\end{array}$} \\
\hline & & & & Endo & Meso & Ecto & & I. $\min ^{-1}$ & ml. $\mathrm{kg}^{-1} \mathrm{~min}^{-1}$ \\
\hline 1967 & 30 & 67.0 & 181.2 & 2.0 & 2.9 & 5.0 & 196 & 3.62 & 54.0 \\
\hline 1970 & 34 & 67.8 & 181.2 & 2.5 & 3.0 & 5.0 & 192 & 3.50 & 51.7 \\
\hline 1974 & 38 & 68.0 & 181.0 & 2.5 & 3.0 & 4.8 & 190 & 3.29 & 48.4 \\
\hline 1978 & 42 & 68.0 & 180.9 & 2.5 & 3.0 & 4.8 & 186 & 3.28 & 48.3 \\
\hline 1982 & 46 & 68.4 & 180.3 & 2.8 & 3.0 & 4.5 & 179 & 3.24 & 47.3 \\
\hline 1986 & 50 & 68.6 & 180.0 & 3.0 & 3.0 & 4.5 & 174 & 3.20 & 46.6 \\
\hline
\end{tabular}

(1979). However, the reduction in maximum oxygen uptake was less than that suggested for sedentary males of approximately $0.5 \mathrm{ml}$. and $0.6 \mathrm{ml} . \mathrm{kg}^{-1} \mathrm{~min}^{-1}$ per year indicated by Quirion et al (1987) and Shephard (1978) respectively.

Hagberg and co-workers in their study of young and older endurance runners, found that maximum oxygen pulse, maximum stroke volume and maximum arteriovenous difference for oxygen in both groups of runners were similar (Hagberg et al, 1985). They therefore suggest that the major haemodynamic difference between middleaged and young athletes during maximal exercise is the lower maximal heart rate of the older runners. The lower maximal heart rate with increased age of the subject in this study (Table I) supports these findings. Though the absolute performance of the subject deteriorated during the 20-year period by about $8-10 \%$, the response to training was similar throughout. Over the twelve training runs each year there is improvement of about $12 \%$ in run times.

As only one subject was studied, only very tentative conclusions can be made. However, the findings do support the view that a loss of functional capacity with age may be minimised by regular physical activity, and the relative improvement over a series of training runs is similar from 30 to 50 years of age.

\section{References}

Åstrand, I., Åstrand, P. O., Hallbäck, I. and Kilbom, A., 1973 "Reduction in maximal oxygen intake with age". J.Appl.Physiol. 35: 649-654.

Astrand, P. O. and Rodahl, K., 1977. A Textbook of Work Physiology. McGrawHill, New York.

Barnard, R. J., Grinditch, G. and Wilmore, J. H., "Physiological characteristics of sprint and endurance masters runners". Med.Sci.Sports 11: 167-171.

Costill, D. L. and Winrow, E., 1970 "A comparison of two middle-aged ultramarathon runners". Res. Quart. 41: 135-139.

Dehn, M. and Bruce, R. A., 1972 “Longitudinal variations in maximal oxygen uptake with age and activity". J.Appl.Physiol. 33: 805-807.

DeVries, H. A., 1980. Physiology of Exercise. Wm. C. Brown Co., Dubuque, lowa.

Hagberg, J. M., Allen, W. K., Seals, D. R., Hurley, B. F., Ehsani, A. E. and Holloway, J. O., 1985 "A haemodynamic comparison of young and older endurance athletes during exercise". J.Appl.Physiol. 58: 2041-46.

Heath, B. H. and Carter, J. E. L., 1967 "A modified somatotype method". Amer.J.Physical Anthropology 27: 57-74.

Quirion, A., de Careful D., Laurencelle, L. et al, 1987 “The physiological response to exercise with special reference to age". J.Sports Med. 27: 143-150.

Robinson, S., Dill, D. B., Tzankoff, S., Wagner, J. and Robinson, R. D., 1975 "Longitudinal studies of ageing in 37 men". J.Appl.Physiol. 38: 263-267.

Shephard, R. J., 1978. Human Physiological Work Capacity. Cambridge Univ. Press, Cambridge, England. 